\title{
Mannitol and proline accumulation in Lycopersicum esculentum during infection of Alternaria alternata and its toxins
}

\author{
Mukesh Meena*, Andleeb Zehra, Manish Kumar Dubey and R. S. Upadhyay
}

\begin{abstract}
Mannitol is important in pathogenesis to counteract antioxidant defences induced in both plant and animal hosts. Proline accumulation in plants under stressed conditions causes the activation of proline biosynthesis. Both mannitol and proline are scavengers of ROS and play an important role in host-pathogen interaction by allowing the fungus to suppress ROS mediated plant responses. The aim of this study was to characterize the effect on mannitol production and proline accumulation during infection of Alternaria alternata and its toxins with tomato plant leading to cell damage or death. Alternaria alternata was isolated from a naturally infected tomato plant and characterized by molecular techniques using PCR amplification. The production of mannitol in plant tissues infected with the pathogen and its toxins were observed and confirmed by using TLC and HPLC analysis that mannitol being produced in plant infected tissues but not in the healthy plant tissues. Proline content also increased in infected tissues at different time intervals. From the result, it is proved that mannitol is somewhere required by A. alternata for its pathogenicity during interaction with tomato which is important for normal disease development. This study demonstrates that mannitol and proline production in tomato plants were increased during treatment with Alternaria alternata as well as its metabolites namely tenuazonic acid (TeA) and alternariol ( $\mathrm{AOH})$.
\end{abstract}

Keywords: Alternaria alternata; Reactive Oxygen Species (ROS); Tenuazonic Acid (TeA); Alternariol (AOH); Mannitol; Proline.

Mukesh Meena* (Corresponding Author), Andleeb Zehra, Manish Kumar Dubey and R. S. Upadhyay

Centre of Advanced Study in Botany, Banaras Hindu University Varanasi-221005, INDIA

\section{Introduction}

Tomato (Lycopersicum esculentum) belongs to the family solanaceae which is an excellent model system to study plant-pathogen interactions [1]. Tomato is second most important vegetable crop grown worldwide having reached a production of more than 160 million tonnes [2]. There have been significant reports on interactions between tomato and other pathogens such as Alternaria alternata, Fusarium oxysporum, Phytopthora infestans, Pseudomonas syringae and Tomato mosaic virus [3].

Mannitol is one of the most frequent sugar alcohols (polyols) found in micro-organisms, plants and animals, such as Alternaria alternata, Cladosporium fulvum, Uromyces fabae, celery, parsley and snapdragon [4-8]. Mannitol is welldocumented for its role in osmoprotection and carbon transport in plants like celery, where mannitol comprises up to $50 \%$ of the translocated carbohydrate [4]. In fungi, several physiological functions have been proposed for mannitol, including carbohydrate storage and translocation, osmoprotection and as antioxidant [9-11].

Mannitol additionally extinguishes reactive oxygen species (ROS) [8], prompting the speculation that it can assume a cell reinforcement part in host-pathogen interactions. Several fungal pathogens require mannitol production and secretion for its pathogenicity [12]. During infecting in tobacco, Alternaria alternata secretes mannitol, which is induced by host leaf extracts [13]. This investigation revealed that fungal pathogens secrete mannitol to reduce the ROS that is involved in plant defences mechanisms. However, pathogen secreted mannitol is catabolised by mannitol dehydrogenase (MTD) which is induced by the pathogen in the plants, thus protecting the plants ROS-mediated defences [14].

Proline is an amino acid which is vital for primary metabolism. Proline may also acts as a protein-compatible hydrotrope [15], and hydroxyl 
radical scavenger [9]. Proline accumulation has been described during situation of drought [16], high salinity [17], high light, UV irradiation, heavy metals [18], oxidative stress [19] and in response to other biotic stresses [20]. Numerous studies have reported proline as an antioxidant suggesting its role as ROS scavenger and singlet oxygen quencher [9, 21]. Exogenous application of proline provides osmoprotection and also enhanced the growth of plants exposed to salt stress [22, 23].

The present study was carried out to examine the effect of Alternaria alternata and its toxins $(\mathrm{Te} \mathrm{A}$ and $\mathrm{AOH})$ on mannitol and proline accumulation during pathogenesis in tomato plants.

\section{Material and Methods}

\section{Isolation and identification of pathogen}

The leaf samples from infected tomato plants were collected and grown on PDA medium. The pathogen was preliminary identified on the basis of morphological characteristics including size, shape and structure of conidia [24] which was further confirmed by ITS amplification using primers AAF2 and AAR3 amplifying ITS regions and 5.8S genes encoding for Alternaria alternata. DNA extraction was carried out as per the method suggested by Doyle and Doyle [25].

\section{Chlorophyll content analysis}

In tomato plant, disease development was also assessed by observing the Chlorophyll content (Chl $a$, Chl $b$ and total chlorophyll) [26]. In this method tomato plants leaves $(0.1 \mathrm{~g})$ that were treated with the pathogen and challenged with toxins of Alternaria species were chopped into small pieces and extracted with $80 \%$ acetone. Chlorophyll contents were measured by taking absorbance at $645 \mathrm{~nm}$ and $663 \mathrm{~nm}$ for chlorophyll $a, b$ and total chlorophyll.

\section{Estimation of mannitol}

\section{Mannitol determination by Thin Layer Chromatography (TLC)}

Mannitol was extracted as described by [27]. Treated leaves were killed in $80 \%$ boiling ethanol and were left overnight. A further extraction was done for 5 minutes with $20 \%$ boiling ethanol. These extracts together form soluble extract containing mannitol. Standard (2\%) which consists of glucose, glycerol and mannitol were spotted along with cell extracts onto silica gel 60 plates (Merck, Darmstadt, Germany) and developed with acetonitrile: ethyl acetate: propanol : water (17:4:4:3) as the mobile phase. The spots were developed by spraying with $0.5 \% \mathrm{KMnO}_{4}$ in $1 \mathrm{~N}$ $\mathrm{NaOH}$.

\section{Mannitol analysis by HPLC}

Mannitol was extracted from the leaves of the infected tomato plants, according to the method described by [28]. Mannitol levels were analysed and quantified by high-performance liquid chromatography (HPLC detector, Photodiode Array Detector PDA detector 2998) at $254 \mathrm{~nm}$. Ten microlitres of sample was injected per run and the system was operated at $0.70 \mathrm{ml} / \mathrm{min}$ with acetonitrile: water in the ratio of $80: 20$ as the mobile phase and using C-18 Waters Spherisorb ${ }^{\circ}$, ODS2, $5.0 \mu \mathrm{m}, 4.6 \mathrm{~mm} \times 250 \mathrm{~mm}$ column at $25^{\circ} \mathrm{C}$ for the separation. Mannitol at $10 \mathrm{mg} \mathrm{l}^{-1}$ was used at the standard and peak area of each sample was quantified. The area of the standard was used to determine the amount of mannitol in the samples.

\section{Estimation of Proline}

Proline was measured as described by [29]. For proline content estimation, $0.5 \mathrm{~g}$ of treated leaf was homogenized in $5 \mathrm{ml}$ of $3 \%$ sulphosalycylic acid and centrifuged at $1,000 \mathrm{rpm}$ to collect the supernatant. The reaction mixture contained $2 \mathrm{ml}$ of filtrate, $2 \mathrm{ml}$ of glacial acetic acid and $2 \mathrm{ml}$ of ninhydrin reagent. The reaction mixture was kept in a boiling water bath at $100^{\circ} \mathrm{C}$ for $1 \mathrm{~h}$ after brick red colour was developed. The reaction mixture was cooled with addition, added $4 \mathrm{ml}$ of toluene and transferred to a separating funnel. After thoroughly mixing, the chromospheres containing toluene was separated. The seprated sample was used for the estimation of proline. The proline concentration was determined from a standard curve. The absorbance of the samples was measured at $520 \mathrm{~nm}$ in a spectrophotometer.

\section{Results}

\section{Isolation and identification of the pathogen}

On the basis of preliminary microscopic examination based on morphological characteristics the pathogen was identified as Alternaria alternata (Fig. 1 A, B). This was further confirmed as the 
same on the basis of pathogen specific primers (Approximately 25 bases in length) coding ITS region and $5.8 \mathrm{~S}$ gene having some regions specific for pathogen as the size of amplicon was found at 341 bp characteristic for Alternaria alternata (Fig. $1 \mathrm{C})$.

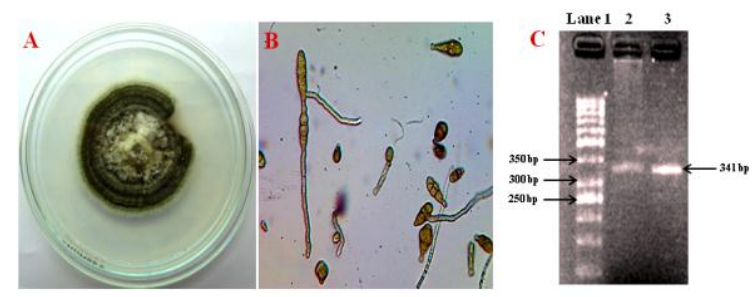

Figure 1. (A) Isolation and purification of pathogen Alternaria alternata on PDA plate isolated from tomato plant (B) Morphology and conidial structure of Alternaria alternata $(\boldsymbol{C})$ Gel electrophoresis of PCR products with primers AAF2/AAR3 of DNA from fungal isolate of Alternaria alternata. Lane 1, molecular weight markers (1 kb ladder); lanes 2-3, Alternaria alternata $(341 \mathrm{bp})$.

\section{Effect on chlorophyll content}

After treatment with metabolites (TeA and $\mathrm{AOH}$ ) and the pathogen, the chlorophyll (chl a, chl b and total chl) content of plant decreased gradually (Fig. 2). Minimum cholorophyll content was observed in pathogen treated plants, followed by $\mathrm{TeA}$ and $\mathrm{AOH}$ with respect to control plants.

Chlorophyll a and chlorophyll b contents were found minimum in pathogen treated plants (chl a $52.74 \%$ and chl b $42.20 \%$ ) followed by metabolite $\mathrm{AOH}$ (chl a $69.23 \%$ and chl b $64.50 \%$ ) and metabolites TeA (chl a $89.67 \%$ and chl b $87.64 \%$ ) challenged plants. Total Chlorophyll content was also found minimum in pathogen treated plants $(46.34 \%)$ followed by metabolite $\mathrm{AOH}(66.58 \%)$ and metabolite TeA (88.40\%) challenged plants with compared to control plants.

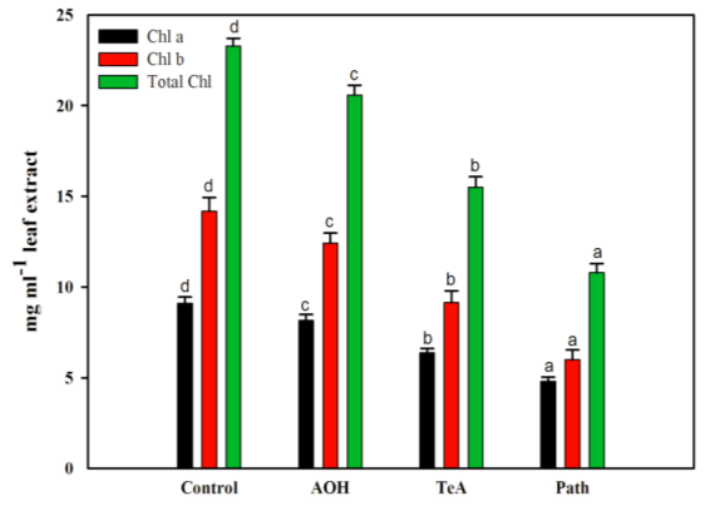

Figure 2. Effect on chlorophyll content in tomato plants treated with pathogen and their metabolites (TeA and AOH) after $48 \mathrm{~h}$. Results were expressed as the mean of three replicates and vertical bars indicate the $\pm S D$ of the mean.

\section{Estimation of mannitol by TLC}

The mannitol ( $\mathrm{Rf}$ value 0.68) increased in the pathogen treated samples as compared to TeA and AOH challenged samples of tomato leaves (Fig. 3). In the pathogen treated sample the spot size was larger as compared to other samples. In control sample (without treatment) the spot was not detected.
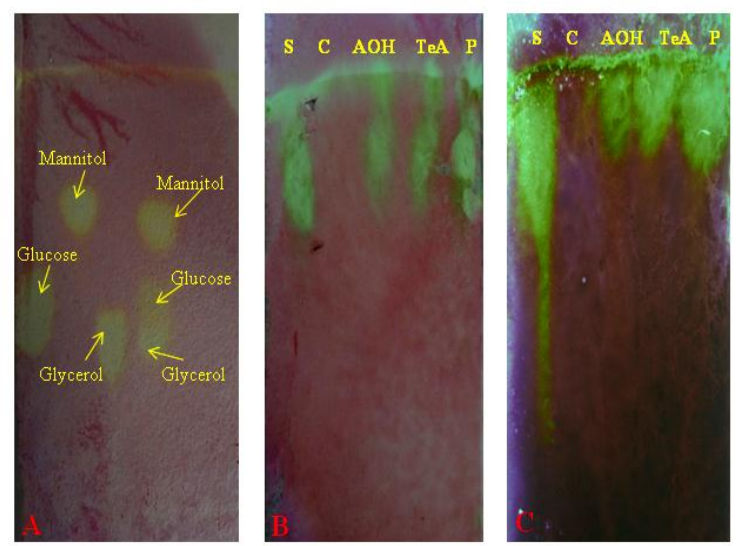

Figure 3. TLC plate showing the mannitol (Rf value 0.68) in tomato plants in different stressed conditions $(\boldsymbol{A})$ Plate showed the mixture of (mannitol, glucose, glycerol) and separation of these three compounds, (B) plate showed the amount of mannitol in stressed condition after $24 \mathrm{~h}$, and $(\boldsymbol{C})$ plate showed amount of mannitol after $48 \mathrm{~h}$

*(S: standard of mannitol, C: control, AOH: Alternariol challenged sample, TeA: Tenuazonic acid challenged sample, $P$ : pathogen treated sample)

\section{Quantitative analysis of mannitol by HPLC}

The result showed that the mannitol production increased during stress conditions. In case of pathogen treated samples highest intensity of mannitol spot was observed at $48 \mathrm{~h}$ after treatment and low intensity of mannitol spot was observed at $24 \mathrm{~h}$ after treatment (Fig. 4). Quantitative estimation of mannitol was performed by using HPLC and the observed results showed that the maximum peak area was found in the case of pathogen treated plant by using mannitol as a standard. The highest content of mannitol was found in pathogen treated plants $(157.3767 \pm 5.87)$ followed by treatment of TeA $(89.0614 \pm 3.01)$ and $\mathrm{AOH}(76.5062 \pm 4.98)$ challenged plants at $48 \mathrm{~h}$ treatment. 


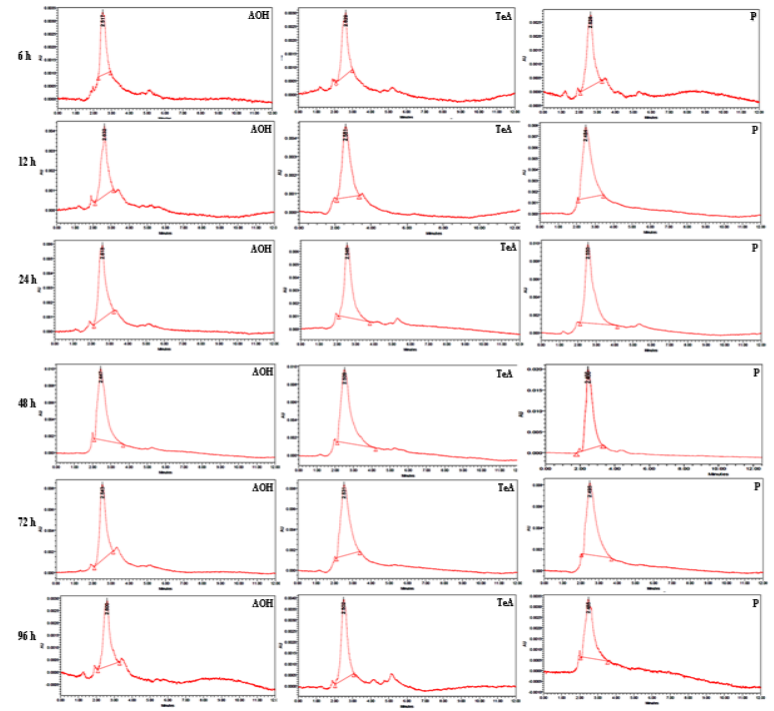

Figure 4. HPLC chromatogram representing the differential concentrations of mannitol (at $0 \mathrm{~h}, 12 \mathrm{~h}, 24 \mathrm{~h}, 48 \mathrm{~h}, 72 \mathrm{~h}$ and 96 h) during pathogen (Alternaria alternata) treated and their metabolites (TeA and AOH) challenged tomato plants samples.

\section{Proline content}

Proline content in tomato plants was found to gradually increase till $72 \mathrm{~h}$ of treatment and then decreased up to $96 \mathrm{~h}$ of treatment (Fig. 5). The maximum activity was seen in pathogen (12.49fold) treated plants followed by TeA (9.63-fold) and minimum in $\mathrm{AOH}$ (7.63-fold) treated plants as compared to the control plant.

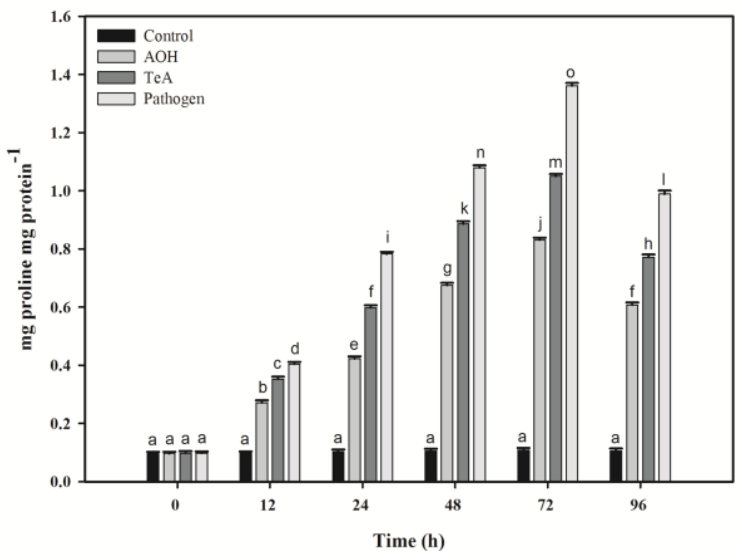

Figure 5. Production of proline at different time intervals in tomato plant by Alternaria alternata and their metabolites (TeA and $\mathrm{AOH}$ ). Results are expressed as the mean of three replicates and vertical bars indicate the $\pm S D$ of the mean.

\section{Discussion}

Leaf chlorophyll content provides useful information about physiological status of plants and also closely related to plant stress and senescence [30]. In this study, the results showed that the chlorophyll contents (chl a, chl b and total chl) were highly reduced in pathogen (Alternaria alternata) treated sample as compared the metabolites (TeA and $\mathrm{AOH})$ challenged samples. Variation in chlorophyll contents in pathogen treated plant could probably be correlated with stomata closure, reduction in $\mathrm{CO}_{2}$ assimilation and transpiration. Thus, substantial enhancement in intercellular $\mathrm{CO}_{2}$ concentration may lead to drop in Photosystem II quantum yields and total chlorophyll content in pathogen infected plant [31].

Mannitol scavanges ROS both in vitro and in vivo [8-9]. This study concludes that in biotic (pathogen) stress conditions tomato plants produced mannitol. The amount of mannitol was highest in pathogen treated plants under the maximum stressed conditions at $48 \mathrm{~h}$ after treatment. Numerous studies have recommended that mannitol may be imperative in pathogenesis to cell reinforcement barriers by both plants and animals [14]. Jennings et al. [15] reported that pathogens secrete mannitol to extinguish ROS amid contamination of tobacco plants, in light of the fact that tobacco (a non-producer of mannitol) communicates a mannitol-debasing compound (MTD) when tested with parasitic elicitors and inducers of plant safeguard reactions.

Biotic stress as well as different abiotic stress causes proline accumulation. The present study concludes that proline accumulation was increased in tomato during Alternaria alternata infection and the stress caused due to its toxins. Its accumulation under various biotic stresses and abiotic stresses, in important crop plants, is considered as a tolerance mechanism. It has also been proposed that its accumulation may be part of a stress signal influencing adaptive responses. It is suggested to act as an osmolyte/compatible as well as a source of nitrogen during recovery from stress. Numerous studies have linked the accumulation of proline to salt stress [32], which may play a protective role against the osmotic potential generated by salt. In addition, proline is proposed to scavenge free radicals [9] and to ameliorate shifts in redox potential by replenishment of the $\mathrm{NADP}^{+}$supply.

\section{Conclusions}

The results obtained during the investigation suggest that significant amount of mannitol was produced in tomato plant to counteract effects of Alternaria alternata and its toxins during infection. Further, this study also reveals that proline accumulation was found to be increased during these interactions. Thus on the basis of current investigation, we can conclude that both mannitol 
and proline play an important role during plantpathogen interactions.

\section{References}

[1] E. Emmanuel and A. A. Levy, "Tomato mutants as tools for functional genomics," Curr. Opin. Plant Biol., 2002, vol. 5, pp. $112-117$.

[2] FAOSTAT, "Food and agriculture organization statistics division," 2012.

[3] A. Di Pietro, M. P. Madrid, Z. Caracuel, J. Delgado-Jarana and M. I. G. Roncero, "Fusarium oxysporum: exploring the molecular arsenal of a vascular wilt fungus," Mol. Plant Pathol., 2003, vol. 4, pp. 315-325.

[4] J. M. H. Stoop, J. D. Williamson and D. M. Pharr, "Mannitol metabolism in plants: a method for coping with stress," Trends Plant Sci., 1996, vol. 1, pp. 139-144.

[5] W. H. Loescher and J. D. Everard, "Regulation of sugar alcohol biosynthesis," in Photosynthesis: Physiology and Metabolism, eds R. C. Leegood, T. D. Sharkey and S. Von Caemmerer, Dordrecht: Kluwer Academic Publishers, 2000, pp. 275-299.

[6] D. H. Jennings, " Polyol metabolism in fungi," Adv. Microb. Physiol., 1984, vol. 25, pp. 149-193.

[7] M. H. A. J. Joosten, L. J. M. Hendrickx and P. G. J. M. De Witt, "Carbohydrate composition of apoplastic fluids isolated from tomato leaves inoculated with virulent or a virulent races of Cladosporium fulvum (syn. Fulvia fulva)," Neth. J. Pl. Path., 1990, vol. 96, pp. 103-112.

[8] R. T. Voegele, M. Hahn, G. Lohaus, T. Link, I. Heiser and K. Mendgen, "Possible roles for mannitol and mannitol dehydrogenase in the biotrophic plant pathogen Uromyces fabae ", Plant Physiol., 2005, vol. 137, pp. 190-198.

[9] N. Smirnoff and Q. Cumbes, "Hydroxyl radical scavenging activity of compatible solutes. Phytochem., 1989, vol. 28, pp. 1057-1060.

[10] D. B. Jennings, M. E. Daub, D. M. Pharr and J. D. Williamson, "Constitutive expression of a celery mannitol dehydrogenase in tobacco enhances resistance to the mannitolsecreting fungal pathogenAlternaria alternata," Plant J., 2002, vol. 32, pp. 41-49.

[11] P. S. Solomon, O. D. C. Waters and R. P. Oliver, "Decoding the mannitol enigma in filamentous fungi," Trends Microbiol., 2007, vol. 15, pp. 257-262.

[12] V. Chaturvedi, B. Wong and S. L. Newman, "Oxidative killing of Cryptococcus neoformans by human neutrophils: evidence that fungal mannitol protects by scavenging reactive oxygen intermediates," J. Immunol., 1996b, vol. 156, pp. 38363840.

[13] D. B. Jennings, M. Ehrenshaft, D. M. Pharr and J. D. Williamson, "Roles for mannitol and mannitol dehydrogenase in active oxygen-mediated plant defense. Proc. Natl. Acad. Sci., U.S.A., 1998, vol. 95, pp. 15129-15133.

[14] M. Meena, P. Vishal, A. Zehra, V. K. Gupta and R. S. Upadhyay, " Mannitol metabolism during pathogenic fungalhost interactions under stressed conditions," Front. Microbiol., 2015, vol. 6, pp. 1019-1026.

[15] V. Srinivas and D. Balasubramanian, "Proline is a proteincompatible hydrotrope,” Langmuir, 1995, vol. 11, pp. 28302833.

[16] N. L. Choudhary, R. K. Sairam and A. Tyagi, "Expression of delta1-pyrroline-5- carboxylate synthetase gene during drought in rice (Oryza sativa L.)," Ind. J. Biochem. Biophys., 2005, vol. 42, pp. 366-370.

[17] Y. Yoshiba, T. Kiyosue, T. Katagiri, H. Ueda, T. Mizoguchi, K. Yamaguchi-Shinozaki, K. Wada, Y. Harada, K. Shinozaki, "Correlation between the induction of a gene for delta 1-pyrroline-5-carboxylate synthetase and the accumulation of proline in Arabidopsis thaliana under osmotic stress. Plant. J., 1995, vol. 7, pp. 751-760.

[18] H. Schat, S. S. Sharma and R. Vooijs, "Heavy metalinduced accumulation of free proline in a metal-tolerant and a nontolerant ecotype of Silene vulgaris," Physiol. Plant, 1997, vol. 101, pp. 477-482.

[19] S. L. Yang, S. S. Lan and M. Gong, "Hydrogen peroxideinduced proline and metabolic pathway of its accumulation in maize seedlings. J. Plant Physiol., 2009, vol. 166, pp. 1694 1699.

[20] E. Haudecoeur, S. Planamente, A. Cirou, M. Tannieres, B. J. Shelp, S. Morera and D. Faure, "Proline antagonizes GABAinduced quenching of quorum-sensing in Agrobacterium tumefaciens," Proc. Natl. Acad. Sci., U.S.A., 2009, vol. 106, pp. 14587-14592.

[21] J. Matysik, Alia, B. Bhalu and P. Mohanty, "Molecular mechanisms of quenching of reactive oxygen species by proline under stress in plants," Curr. Sci., 2002, vol. 82, pp. 525-532.

[22] P. H. Yancey, "Compatible and counteracting solutes" In "Cellular and Molecular Physiology of Cell Volume Regulation" (S. K. Strange, Ed.), 1994, pp. 81-109, CRC Press, Boca Raton.

[23] L. N. Csonka and A. D. Hanson, "Prokaryotic osmoregulation: genetics and physiology," Annu. Rev. Microbiol., 1991, vol. 45, pp. 569-606.

[24] M. R. Safari Motlagh and B. Kaviani, "Characterization of new bipolaris spp., the causal agent of rice brown spot disease in the north of Iran. Int. J. Agric. Biol., 2008, vol. 10, pp. 638-642. [25] J. J. Doyle and J. L. Doyle, "A rapid DNA isolation procedure for small quantities of fresh leaf tissue," Phytochem. Bull., 1987, vol. 19, pp. 11-15.

[26] H. K. Lichtenthaler and A. R. Wellburn, "Determinations of total carotenoids and chlorophylls a and b of leaf extracts in different solvents," Biochem. Soc. Trans., 1983, vol. 11, pp. 591-592.

[27] T. Dulermo, C. Rascle, G. Billon-Grand, E. Gout, R. Bligny and P. Cotton, "Novel insights into mannitol metabolism in the fungal plant pathogen Botrytis cinerea," Biochem. J., 2010, vol. 427, pp. 323-332.

[28] T. Dulermo, C. Rascle, G. Billon-Grand, E. Gout, R. Bligny and P. Cotton, "Novel insights into mannitol metabolism in the fungal plant pathogen Botrytis cinerea," Biochem. J., 2010, vol. 427, pp. 323-332

[29] L. E. Bates, R. P. Waldren and I. D. Teare, "Rapid determination of free proline for water stress studies," Plant and Soil, 1973, vol. 39, pp. 205-207.

[30] M. N. Merzlyak, A. A. Gitelson, O. B. Chivkunova and V. Y. Rakitin, "Non-destructive optical detection of leaf senescence and fruit ripening," Plant Physiol., 1999, vol. 106, pp.135-141. [31] A. N. Petit, N. Vaillant, M. Boulay, C. Clement and F. Fontaine, "Alteration of photosynthesis in grapevines affected by Esca," Phytopathology, 2006, vol. 96, pp. 1060-1066.

[32] A. Aziz, J. Martin-Tanguy and F. Larher, "Salt stressinduced proline accumulation and changes in tyramine and polyamine levels are linked to ionic adjustment in tomato leaf discs," Plant Sci., 1999, vol. 145, pp. 83-91. 